\title{
ISOTROPIC AND ANISOTROPIC FLOW RELATIONS FOR ICE DYNAMICS
}

\author{
by \\ T.H. Jacka \\ (Australian Antarctic Division, Channel Highway, Kingston, Tasmania 7050, Australia) \\ and
}

W.F. Budd

(Meteorology Department, University of Melbourne, Parkville, Victoria 3052, Australia)

\section{ABSTRACT}

A flow relation for the minimum strain-rates for isotropic ice is presented. This flow relation has been compiled from laboratory tests in shear and compression, and covers the temperature and stress ranges typical of natural ice masses. However, the ice in natural ice masses is mostly anistropic. Three cores drilled at Law Dome, Antarctica, are used as examples to illustrate some of the different anisotropies that develop in ice masses in relation to the stress configurations and accumulated strains.

For the shear- or compression-stress configurations, anistropic flow rates can be derived as enhancements of the minimum isotropic flow rates for the particular stress, temperature, and stress configuration. For compression, this enhancement asymptotically approaches 3. For shear, the enhancement may be as high as 8 . For combinations of shear and compression, further tests are required.

\section{INTRODUCTION}

The interdependence between ice-crystal-orientation fabrics and flow rates has been recognized for some time (e.g. Steinemann, 1958; Budd, 1972; Kamb, 1972). Only recently, however, have laboratory experiments been carried out to the high strains (in excess of 10\%) required to establish the various crystal anisotropies found within natural ice masses. With these experiments, tertiary flow rates have also been measured in some of the stress configurations found in the ice masses. In addition, recent work (Jacka, unpublished) has further examined the flow rates for isotropic ice at the lower temperatures and stresses typical of polar ice masses.

This paper has three aims: (1) to illustrate the similarity between crystal-orientation fabrics obtained in the laboratory and those found in natural ice masses. This is done by comparison of laboratory-developed fabrics with those from three ice cores extracted from Law Dome, Antarctica; (2) to present an improved flow relation for isotropic ice; and (3) to propose suitable enhancement factors (over isotropic minimum strain-rates) for tertiary anisotropic strain-rates, given particular crystal-orientationfabric patterns, stress configurations, and total strains.

\section{A FLOW LAW FOR ISOTROPIC ICE MINIMUM STRAIN-RATE}

Laboratory studies of the flow of isotropic polycrystalline ice show a power-law relation between stress and minimum strain-rate (cf. Glen, 1958). This has been shown (Budd and Jacka, in press) to hold for ice under different stress configurations (to $\pm 50 \%$ ), provided rootmean-square values (i.e. the conversions to octahedral or effective values) of the stress and strain-rate components are used.

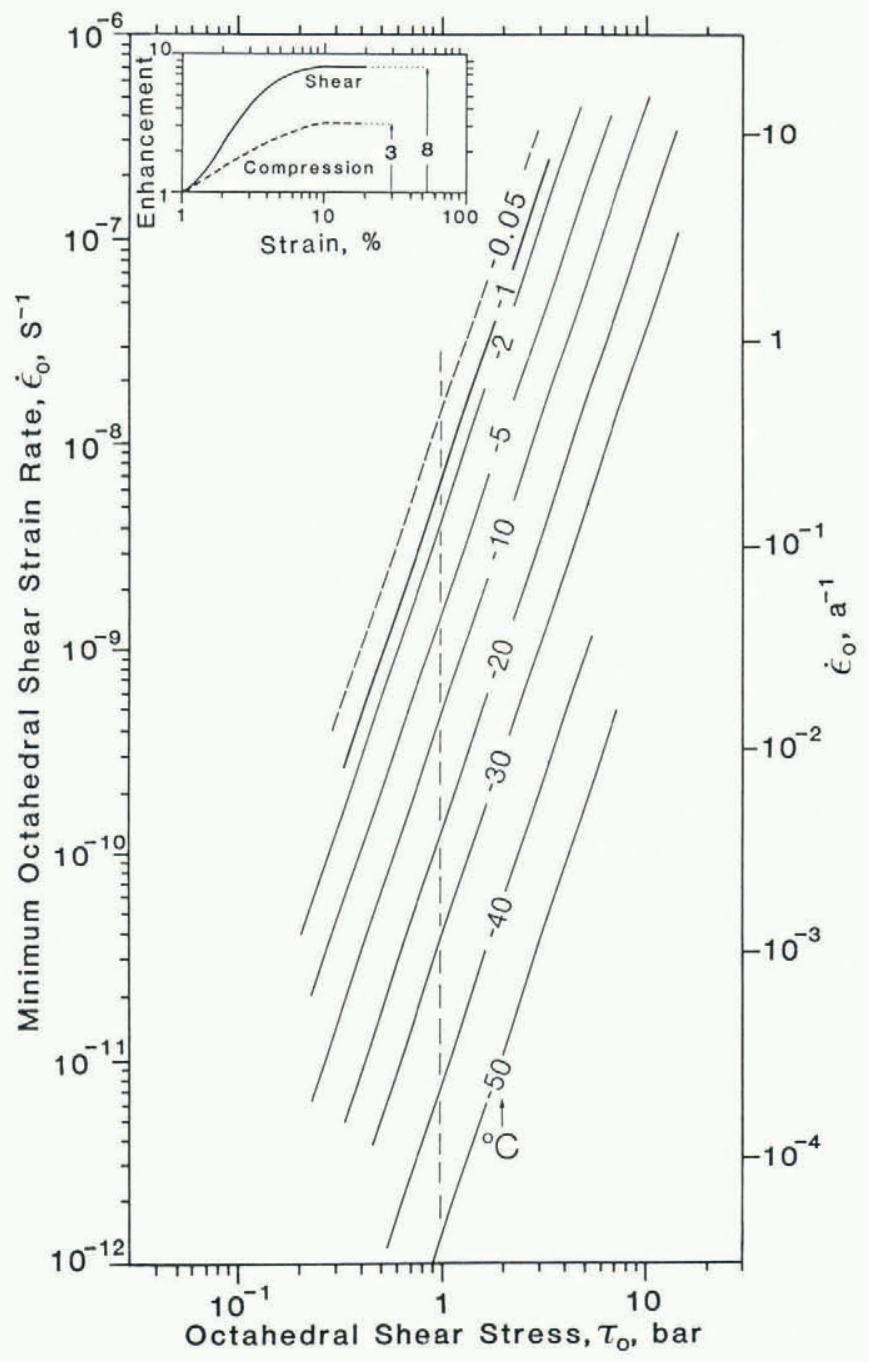

Fig. 1. A flow relation for isotropic ice minimum strain-rates from shear and compression tests, and for the temperature and stress range found in natural ice masses (after Budd and Jacka, in press). Enhancement factors for anisotropic ice in shear and in compression are shown (inset) as a function of total strain.

The power-law relation with index $n=3$ has been shown to be valid for the main range of stresses and temperatures experienced within natural ice masses. Figure 1 illustrates the relation obtained between minimum octahedral shear strain-rate and octahedral shear stress over a range of temperatures. Table I provides values of strain-rate from Figure 1 in a form that may be useful for computer modelling of ice masses. Both Figure 1 and Table $I$ have 
TABLE I. MINIMUM CREEP RATES FOR ISOTROPIC ICE AS A FUNCTION OF STRESS AND TEMPERATURE

Temp.

${ }^{\circ} \mathrm{C}$
Octahedral shear stress

bar

1.0

2.0

Minimum octahedral shear strain-rate

$\begin{array}{ll}-0.05 & 2.4 \times 10^{-10} \\ -1.0 & 1.1 \times 10^{-10} \\ -2.0 & 6.8 \times 10^{-11} \\ -5.0 & 2.5 \times 10^{-11} \\ -10 & 9.0 \times 10^{-12} \\ -20 & 2.0 \times 10^{-12} \\ -30 & \\ -40 & \\ -50 & \end{array}$

$\begin{array}{ll}\mathrm{s}^{-1} & \\ 1.4 \times 10^{-8} & 1.0 \times 10^{-7} \\ 6.8 \times 10^{-9} & 5.7 \times 10^{-8} \\ 4.1 \times 10^{-9} & 3.3 \times 10^{-8} \\ 1.5 \times 10^{-9} & 1.2 \times 10^{-8} \\ 5.2 \times 10^{-10} & 4.0 \times 10^{-9} \\ 1.3 \times 10^{-10} & 1.0 \times 10^{-9} \\ 3.6 \times 10^{-11} & 3.0 \times 10^{-10} \\ 8.0 \times 10^{-12} & 7.0 \times 10^{-11} \\ 1.5 \times 10^{-12} & 1.2 \times 10^{-12}\end{array}$

$9.0 \times 10^{-7}$
$4.2 \times 10^{-7}$
$2.4 \times 10^{-7}$
$1.0 \times 10^{-7}$
$3.2 \times 10^{-7}$
$8.0 \times 10^{-8}$
$2.3 \times 10^{-8}$
$5.5 \times 10^{-9}$
$9.5 \times 10^{-10}$ been compiled from laboratory experiments in shear, compression, and extension. These experiments, on initially isotropic ice, cover the octahedral stress range $0.25-10$ bar and temperature range $0^{\circ}$ to $-50^{\circ} \mathrm{C}$. Tests at temperatures as cold as $-32.5^{\circ} \mathrm{C}$ have extended beyond minimum strain-rate which occurs at an octahedral strain of $\sim 1 \%$.

The data conform to a relation between octahedral stress, $\tau_{0}$, and strain-rate, $\dot{\varepsilon}_{0}$ of the form

$$
\dot{\varepsilon}_{0}=k_{\theta} \tau_{0}^{n}
$$

with $n=3$ and where at $-10^{\circ} \mathrm{C}, k_{\theta}=5.2 \times 10^{-10} \mathrm{bar}^{-3} \mathrm{~s}^{-1}$ and the values of $k_{\theta}$ at other temperatures are obtained from Table I. For an indication of the uncertainties in these values of $n$ and $k$, references should be made to Jacka (unpublished), Jacka (1984), or Mellor and Cole (1982).

\section{THE DEVELOPMENT OF CRYSTAL ANISOTROPIES}

Ice within natural ice masses is not isotropic; crysta anisotropies develop due to the total strain experienced by the ice under different anisotropic stress configurations.

Figure 2 shows the cross-section of an oversnow traverse line (which approximates an ice-flow line) on Law Dome, Antarctica, from the summit of this ice cap to Cape Folger on the coast. Particle trajectories (derived from computer modelling of the flow line) are shown together with positions and depths of ice-core drilling sites. Crystalorientation fabrics from the cores collected at sites 1, 3, and 8 are shown with the profile in Figure 2.

The ice deformation in the upper zones of the ice sheet is dominated by a net vertical compression of $\sim 10^{-3}$ $\mathrm{a}^{-1}$. In the deeper zones, horizontal shear dominates, ranging from $\sim 10^{-3} \mathrm{a}^{-1}$ near the summit to $\sim 3 \times 10^{-2} \mathrm{a}^{-1}$ near the coast (Pfitzner, 1980). Bore-hole studies (e.g. Russell-Head and Budd, 1979) show that the basal ice is characterized by high variability including relatively stagnant zones with large crystals.

The crystal-orientation fabrics from the upper layers in each of the three ice cores of Figure 2 exhibit a random pattern. For the core from site 1 , which is very near to the summit of Law Dome, a small amount of central tendency is evident in the crystal-orientation fabrics from 205 and $244 \mathrm{~m}$ depth. The fabric from $318 \mathrm{~m}$ depth exhibits a strong small-circle girdle pattern. This pattern has been found in the laboratory to be associated with compression to strains in excess of $\sim 10 \%$ (e.g. Wilson and Russell-Head, 1982; Jacka and Maccagnan, 1984; Gao and Jacka, 1987), and is shown in Figure 3a to be similar to a fabric developed in the laboratory by Jacka and Maccagnan. In addition, creep rates for ice from this core have been shown to be particularly close to those for laboratory-prepared ice after comparable total strains and given the same stress configurations (Gao and Jacka, 1987).

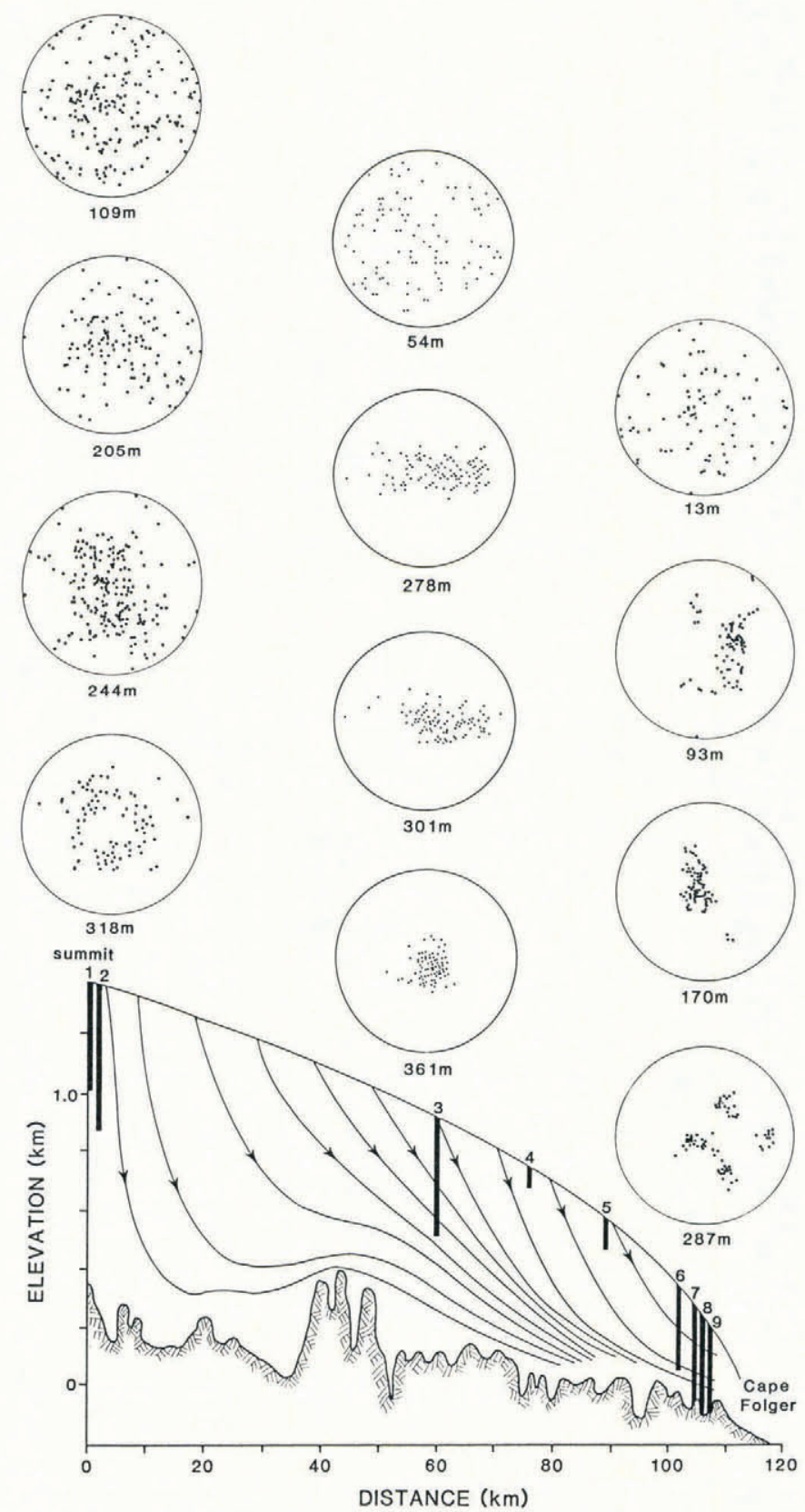

Fig. 2. A cross-section of a traverse line from the summit of Law Dome to Cape Folger on the coast. Particle trajectories are shown along with the positions of ice-core drilling sites. Crystal-orientation fabrics are shown for the ice cores from sites 1, 3 (from $\mathrm{Li}$ and others, 1988), and 8 (from Thwaites and others, 1984). 

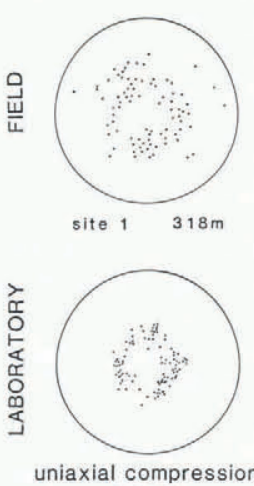

$32.5 \%$ (b)
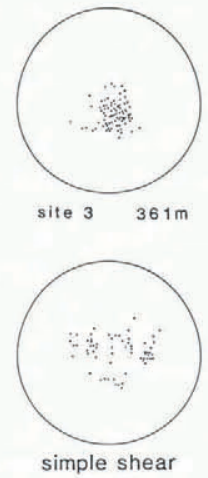

$200 \%$ (c)
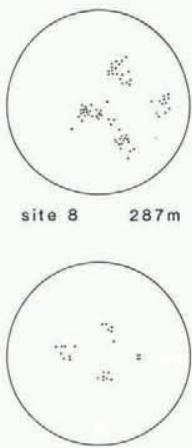

compression to $27.6 \%$ then stress reduction over 60 days at $-3.3^{\circ} \mathrm{C}$
Fig. 3. Comparison of crystal-orientation fabrics from the ice cores with those developed in the laboratory for different stress configurations: (a) compression, (b) simple shear, and (c) compression followed by stress reduction. Laboratory-developed fabrics are from (a) Jacka and Maccagnan (1984); (b and c) Gao (thesis in preparation).

The development of a single near-vertical maximum pattern, as illustrated by the crystal fabrics from site 3 and by the fabrics at 93 and $170 \mathrm{~m}$ depth from site 8 , is associated (from laboratory tests) with simple shear to high strains (e.g. Russell-Head and Budd, 1979; Bouchez and Duval, 1982). In Figure 3b, the fabric from site 3 at $301 \mathrm{~m}$ depth is compared with a weak near-vertical maximum fabric from Gao (thesis in preparation) developed in a simple shear experiment after a total octahedral strain of $200 \%$.

Alley (in press) and Azuma and Higashi (1984) have suggested that, provided no new grains are formed, a single near-vertical maximum fabric pattern can also develop as a consequence of vertical compression to very high strains. Gao (thesis in preparation) has conducted compression experiments to $60 \%$ strain, resulting in a small-circle girdle fabric pattern with the same cone half-angle $\left(\sim 27^{\circ}\right)$ as had been developed at $32 \%$ strain. In addition, Gao (thesis in preparation) has conducted compression tests to $20 \%$ strain on ice initially exhibiting a single-maximum pattern, and these tests resulted in the development from the single maximum to a small-circle girdle. Alley (in press) explains results such as those obtained by $\mathrm{Gao}$ as a consequence of the formation of new grains.

A multiple-maxima fabric pattern is exhibited in the ice from near the base of site 8 , at a depth of $287 \mathrm{~m}$. Fabrics similar to this have been found elsewhere, typically near the base of ice sheets and particularly at locations where the basal ice temperature is warmer than $-10^{\circ} \mathrm{C}$ (e.g. Gow and Williamson, 1976; Matsuda and Wakahama, 1978), and within temperate glaciers (Kamb and Shreve, 1963). This ice invariably consists of large crystals, consistent with the warmer temperatures in which it is found. Comparable fabri: patterns (Fig. 3c) have also been developed in the laboratory through crystal growth associated with stress relaxation and annealing (Gao, thesis in preparation). Gao first strained the ice in uniaxial compression through $27.6 \%$ octahedral to establish a small-circle girdle fabric pattern, and then reduced the stress (initially 3 bar octahedral) to zero over a period of $60 \mathrm{~d}$. The test temperature was $-3.3^{\circ} \mathrm{C}$. A similar multiple-maxima fabric was obtained by Azuma and Higashi (1984) through vertical unconfined compression of ice with $c$-axes oriented near $45^{\circ}$, with a temperature increase from $-15.8^{\circ}$ to $-2.8^{\circ} \mathrm{C}$.

In therefore appears that the various crystal-orientation fabric patterns found in the ice cores from Law Dome and elsewhere can be produced in the laboratory by deformation with similar total strain and dominant stress configuration.

\section{A FLOW LAW FOR ANISOTROPIC ICE AND TERTIARY FLOW}

The flow rate for anisotropic polycrystalline ice in "easy glide" (compatible stress configuration and crystal fabric) can be considered as an enhancement of strain-rate over the minimum isotropic value. For compression of ice exhibiting a strong small-circle girdle fabric pattern, this enhancement factor becomes asymptotic to about 3 after about $15 \%$ strain (Jacka and Maccagnan, 1984). For simple shear of ice exhibiting a strong single-maximum pattern, the easy glide enhancement factor may be as high as 8 (Russell-Head, 1985). For compression or shear, then, the flow relation illustrated in Figure 1 can be used for anisotropic ice, provided an enhancement factor is incorporated. The enhancement, as a function of total strain, is given in the inset to Figure 1.

Thus, for the tertiary steady-state octahedral strainrates, $\dot{\varepsilon}_{0)_{3}}$ of anisotropic ice, where the anisotropy has been developed by the deformation in compression or shear, Equation (1) is replaced by

$$
\begin{aligned}
& \dot{\varepsilon}_{0) 3}=3 k_{\theta} \tau_{0}^{3} \text { for compression, and } \\
& \dot{\varepsilon}_{0) 3}=8 k_{\theta} \tau_{0}^{3} \text { for shear }
\end{aligned}
$$

where the values of $k_{\theta}$ are obtained from Table I.

Russell-Head (unpublished) determined relative shear rates for several crystal-fabric patterns including vertical girdles, two maxima at $\sim 40^{\circ}$, and multiple maxima. The stress configuration throughout most of a natural ice mass, however, is a combination of compression and shear. Laboratory tests in this combined stress configuration have not yet been satisfactorily carried out to the high strains required to attain tertiary steady-state creep.

To establish a flow relation for anisotropic ice in the combined stress configuration, the conventional approach has been to consider the octahedral shear stress and strain-rate, and to assume that the same form of relation (Equation (1)) holds for anisotropic ice as for isotropic ice.

For a combined stress situation with normal stress and strain-rates $\sigma$ and $\dot{\varepsilon}$ and shear stress and strain-rates $\tau$ and $\dot{\gamma}$, respectively, the octahedral relations are given (Jacka, unpublished) by

$$
\begin{aligned}
& \tau_{0}=\frac{(2)}{3}^{\frac{1}{2}}\left(\sigma^{2}+3 \tau^{2}\right)^{\frac{1}{2}} \quad \text { and } \\
& \dot{\varepsilon}_{0}=\frac{(2)^{\frac{1}{2}}}{3}\left(\dot{\varepsilon}^{2}+3 \dot{\gamma}^{2}\right)^{\frac{1}{2}} .
\end{aligned}
$$

Although Equation (1) with these values may be expected to hold for isotropic ice, the applicability to tertiary flow or anisotropic ice still needs investigation. In fact, the addition of a high normal stress to a well-established tertiary flow under simple shear with a well-developed single-maximum crystal fabric may be expected to cause recrystallization and a decrease of the shear strain-rate rather than the increase implied by Equations (1), (4), and (5). This illustrates the importance of experimental work to study tertiary flow under combined stress situations.

\section{CONCLUSIONS}

A flow relation for isotropic ice minimum strain-rate has been presented. For anisotropic ice exhibiting the development of a small-circle girdle crystal-orientation fabric and which is subjected to vertical compression, an enhancement over the isotropic minimum flow rate of up to 3 seems appropriate. If the fabric pattern exhibits development of a single near-vertical maximum under horizontal shear, an enhancement of up to 8 seems appropriate.

Further experimental work is required to establish flow rates of ice exhibiting other fabric patterns and subjected to other stress configurations. For shear and compression combined, the octahedral relations imply higher flow rates than in shear or compression alone. Although this may be the case for isotropic ice, it is not expected for anisotropic ice. Until further tests are carried out, it is recommended for this combined stress configuration that tertiary anisotropic flow rates be estimated by applying an enhancement estimated from the inset to Figure 1 according 
to the ratio of the compressive stress to the shear stress and to the total strain. For strains in excess of $\sim 15 \%$, this estimated enhancement will fall between 3 and 8 .

\section{REFERENCES}

Alley, R.B. In press. Fabric in polar ice sheets: development and prediction. Science.

Azuma, N. and A. Higashi. 1984. Mechanical properties of Dye 3 Greenland deep ice cores. Ann. Glaciol., 5, 1-8.

Bouchez, J.L. and P. Duval. 1982. The fabric of polycrystalline ice deformed in simple shear experiments in torsion, natural deformation and geometrical interpretation. Textures Microstruc., 5, 171-190.

Budd, W.F. 1972. The development of crystal orientation fabrics in moving ice. Z. Gletscherkd. Glazialgeol., 8(1-2), 65-105.

Budd, W.F. and T.H. Jacka. In press. A review of ice rheology for ice sheet modelling. Cold Reg. Sci. Technol.

Gao, X.Q. and T.H. Jacka. 1987. The approach to similar tertiary creep rates for Antarctic core ice and laboratory prepared ice. J. Phys. (Paris), 48, Colloq. Cl, 289-295. (Suppl. au 3.)

Glen, J.W. 1958. The flow law of ice: a discussion of the assumptions made in glacier theory, their experimental foundations and consequences. International Association of Scientific Hydrology Publication 47 (Symposium of Chamonix 1958 - Physics of the Motion of Ice), 171-183.

Gow, A.J. and T. Williamson. 1976. Rheological implications of the internal structure and crystal fabrics of the West Antarctic ice sheet as revealed by deep core drilling at Byrd Station. CRREL Rep. 76-35.

Jacka, T.H. 1984. The time and strain required for development of minimum strain rates in ice. Cold Reg. Sci. Technol., 8(3), 261-268.

Jacka, T.H. Unpublished. Experimental investigations of the flow of ice. (Ph.D. thesis, University of Melbourne, 1987.)

Jacka, T.H. and M. Maccagnan. 1984. Ice crystallographic and strain rate changes with strain in compression and extension. Cold Reg. Sci. Technol., 8(3), 269-286.
Kamb, W.B. 1972. Experimental recrystallization of ice under stress. In Heard, H.C., I.Y. Borg, N.L. Carter, and C.B. Raleigh, eds. Flow and fracture of rocks. Washington, DC, American Geophysical Union, 211-241. (Geophys. Monogr. 16.)

Kamb, W.B. and R.L. Shreve. 1963. Texture and fabric of ice at depth in a temperate glacier. Trans. Am. Geophys. Union, 44, 103.

Li, J., Xie Zichu, and Huang M. 1988. Fabrics of the ice cores from BHQ on Law Dome ice cap, Antarctica. Kexue Tongbao, 33(3), 216-220.

Matsuda, M. and G. Wakahama. 1978. Crystallographic structure of polycrystalline ice. J. Glaciol., 21(85), 607-620.

Mellor, M. and D. Cole. 1982. Deformation and failure of ice under constant stress or constant strain rate. Cold Reg. Sci. Technol., 5(3), 201-219.

Pfitzner, M.L. 1980. The Wilkes Ice Cap Project, 1966. ANARE Sci. Rep., Ser. A(4), Glaciol. (Publ. 127.)

Russell-Head, D.S. 1985. Shear deformation of ice to large strains. ANARE Res. Notes 28, 118-121.

Russell-Head, D.S. Unpublished. Ice sheet flow from borehole and laboratory studies. (M.Sc. thesis, University of Melbourne, 1979.)

Russell-Head, D.S. and W.F. Budd. 1979. Ice-sheet flow properties derived from bore-hole shear measurements combined with ice-core studies. J. Glaciol., 24(90), 117-130.

Steinemann, S. 1958. Résultats expérimentaux sur la dynamique de la glace et leurs corrélations avec le mouvement et la pétrographie des glaciers. International Association of Scientific Hydrology Publication 47 (Symposium of Chamonix 1958 - Physics of the Motion of Ice), 184-198.

Thwaites, R.J., C.J.L. Wilson, and A.P. McCray. 1984. Relationship between bore-hole closure and crystal fabrics in Antarctic ice core from Cape Folger. J. Glaciol., 30(105), 171-179.

Wilson, C.J.L. and D.S. Russell-Head. 1982. Steady-state preferred orientation of ice deformed in plain strain at $-1{ }^{\circ}$ C. J. Glaciol., 28(98), 145-160. 